\title{
ANÁLISE DA VARIABILIDADE GENÉTICA DE ACESSOS DE Psidium spp. (MYRTACEAE) AVALIADOS QUANTO À REAÇÃO A Meloidogyne enterolobii ${ }^{1}$
}

\author{
EDUARDO JOSÉ ALMEIDA², ESTER WICKERT ${ }^{3}$, JAIME MAIA SANTOS ${ }^{4}$, \\ ANTONIO BALDO GERALDO MARTINS ${ }^{5}$
}

RESUMO - Este trabalho teve por objetivo a caracterização molecular de 13 acessos de Psidium spp. (Myrtaceae) identificados previamente quanto à reação ao nematoide da goiabeira. A extração do DNA das amostras foi executada conforme o protocolo de Shillito e Saul (1988). Os marcadores moleculares do tipo fAFLP, foram obtidos utilizando-se do 'fAFLP Regular Plant Genomes Fingerprinting Kit' (Applied Biosystems do Brasil Ltda.) onde foram testadas 24 combinações seletivas de primers, das quais 18 apresentaram amplificação que gerou 272 marcadores polimórficos. Para a análise dos marcadores, foram utilizados os softwares GeneScan (ABI Prism versão 1.0) e Genotyper (ABI Prism versão 1.03), e os dados coletados foram transformados em matriz binária que foi analisada no software PAUP (Phylogenetic Analysis Using Parcimony - versão 3.01). Foram também calculados índices de distância genética intra e interespecífica entre os materiais. Verificou-se que os marcadores AFLP foram eficientes na discriminação dos acessos entre si, bem como apontou similaridade genética entre os acessos identificados como resistentes ao nematoide Meloidogyne enterolobii, característica esta passível de exploração no futuro.

Termos para indexação: resistência de plantas a doenças, fruta tropical, Psidium guajava, nematoide de galha, marcadores genéticos.

\section{ANALYSIS OF GENETIC VARIABILITY OF Psidium spp. (MYRTACEAE) ACCESS EVALUATED FOR RESISTANT TO Meloidogyne enterolobii}

\begin{abstract}
This study aimed to characterize molecular of 13 accessions of Psidium spp. (Myrtaceae) that was been identified for the reaction to rootknot guava nematode. The DNA extraction of the samples was carried according to the protocol of Shillito \& Saul (1988). The molecular markers type fAFLP, were obtained from 'fAFLP Regular Plant Genomes Fingerprinting Kit' (Applied Biosystems from Brasil Ltda.) and were tested 24 selectives combinations of primers, of which 18 showed amplification that produced 272 polymorphic markers. To the analysis of the markers were employed the softwares GeneScan (ABI Prism versão 1.0) and Genotyper (ABI Prism version 1.03), and the data collected were transformed into a binary matrix that was analyzed in the software PAUP (Phylogenetic Analysis Using Parcimony - version 3.01). Were calculated genetic distance índex intra and interespecific between the genotipes. It was found that the AFLP markers were efficient in the discrimination between accessions, as well as in showing genetic similarity among accessions identified as resistant to the nematode Meloidogyne enterolobii, which could be discussed in the future.
\end{abstract}

Index Terms: disease resistance, tropical fruit, Psidium guajava, root knot nematodes, genetic marker.

\footnotetext{
${ }^{1}$ (Trabalho 012-12). Recebido em: 03-01-2012. Aceito para publicação em: 30-05-2012.

${ }^{2}$ Eng. Agro. Prof. D.Sc. de Fruticultura do Departamento de Agroecologia do Centro de Ciências Agrárias da Universidade Federal de São Carlos, Araras. Rod. Anhanguera, Araras-SP. E-mail: ealmeida@cca.ufscar.br

${ }^{3}$ Eng $^{\mathrm{a}}$. Agro. D.Sc. Pesquisadora da Epagri, Estação Experimental de Itajaí-SC, C. P. 277 CEP 88301-970. E-mail: esterwickert@ epagri.sc.gov.br.

${ }^{4}$ Eng. Agro. Prof. D.Sc. de Fruticultura do Departamento de Produção Vegetal da FCAV-Unesp. Via de acesso Prof. Paulo Donato Castelane, s/n. E-mail: baldo@fcav.unesp.br

${ }^{5}$ Eng. Agro. Prof. D. Sc. de Nematologia do Departamento de Fitossanidade da Fcav-Unesp. Via de acesso Prof. Paulo Donato Castelane, s/n. E-mail: jmsantos@fcav.unesp.br
} 


\section{INTRODUÇÃO}

A goiabeira ( $P$. guajava) é uma espécie da família Myrtaceae que engloba mais de 70 gêneros e 2.800 espécies distribuídas nas regiões tropicais e subtropicais do globo, principalmente nas Américas e na Austrália. O gênero Psidium compreende cerca de 150 espécies, dentre as quais se destacam $P$. guajava L., $P$. cattleyanum Sabine e $P$. guineense Swartz ou $P$. araça Raddali (PEREIRA; NACHTIGAL, 2003).

O Brasil possui grandes áreas com condições edafoclimáticas favoráveis à produção comercial de goiaba (Psidium guajava L.). Esse aspecto tem relevância, não apenas pelo valor nutritivo da fruta, mas também pela perspectiva que representa no incremento da produção agrícola, na ampliação da atividade industrial e no potencial de exportação (ROZANE; COUTO, 2003). Porém, desde 1989, vêm sendo relatados severos danos à cultura, causados por Meloidogyne enterolobii Yang \& Einsenback, 1983 (Sin.: M. mayaguensis Rammah \& Hirschmann, 1988) (ALMEIDA et al., 2009).

Esse nematoide de galha é altamente agressivo e representa séria ameaça à cultura da goiaba e a outras culturas do agronegócio nacional (SOUZA et al., 2006). Conforme estimativa de Pereira et al. (2009), no perímetro irrigado de Pernambuco e Bahia, os prejuízos diretos somaram R $\$ 112,7$ milhões, mais a dispensa de 3.703 postos de trabalho,com prejuízos a jusante e a montante da propriedade produtora de goiabas. Esses dados evidenciam o forte impacto econômico e social causado pelo nematoide na produção dessa frutífera, com o agravante de não haver ainda o controle efetivo da doença.

No manejo integrado de nematoides, o uso de cultivares resistentes é uma alternativa vantajosa e econômica, comparado ao emprego de nematicidas. Por resistência, entende-se a habilidade de uma planta suprimir a reprodução ou o desenvolvimento do nematoide (ROBERTS et al., 1998). O termo resistência, em nematologia, frequentemente também é usado para se referir à capacidade de suprimir a doença, especialmente a formação de galhas em raízes.

Espécies pertencentes à família Mirtaceae, com resistência a $M$. enterolobii, possibilitariam seu uso como porta-enxerto para as variedades comerciais de goiabeira. A existência de grande número de materiais geneticamente diferentes, mas que mantêm alguma afinidade morfofisiológica aumenta a chance de haver compatibilidade na enxertia entre diferentes espécies em Psidium (HARTMAN et al.,1997). Portanto, é imprescindível a busca por materiais resistentes dentro de Mirtaceae e o estudo da viabilidade do uso desses materiais como porta-enxertos.
Carneiro et al. (2007) e Almeida et al. (2009) encontraram fontes de resistência ao nematoide em acessos de Psidium cattleyanum. Contudo, o uso desses materiais diretamente como porta-enxerto vem mostrando-se impraticável, demandando trabalhos de melhoramento com essas espécies.

Tecnologias de marcadores moleculares de DNA estão sendo cada vez mais utilizadas em programas de melhoramento, com o objetivo de aumentar a eficiência de seleção e caracterização de germoplasmas e a maximização dos ganhos genéticos, permitindo aos melhoristas o acesso e a seleção da variabilidade de DNA.

Marcadores moleculares são características de DNA que diferenciam dois ou mais indivíduos e têm base mendeliana. São moléculas como DNA ou proteínas que marcam uma região ou regiões do genoma ligadas a alguma característica de interesse. Características morfológicas e agronômicas têm a desvantagem de serem influenciadas pelos fatores do ambiente e podem não representar a real similaridade ou diferença entre os indivíduos. Por outro lado, marcadores genéticos representam estritamente a variação genética, não sofrendo influência ambiental (WEISING et al., 1995).

Marcadores de DNA são eficientes na identificação de marcas moleculares ligadas a genes de resistência a doenças e pragas, facilitando, assim, a introgressão desses genes em espécies e cultivares de interesse comercial, através de programas de melhoramento (FERREIRA; GRATTAPAGLIA, 1998). Conforme Young (1998), citado por Aukar (2003), a resistência das plantas aos nematoides tem sido caracterizada por uma grande variação do número de genes. A resistência a $M$. incognita em tomateiro é caracterizada por ser do tipo monogênica, enquanto a resistência a Heterodera glycines em soja é do tipo oligogênica, ou seja, é controlada por poucos genes (AUKAR, 2003).

Este trabalho teve por objetivo a caracterização molecular de acessos de Myrtaceae avaliados em trabalhos prévios de reação a $M$. enterolobii, passíveis de serem utilizados como porta-enxertos para cultivares comerciais de goiabeira.

\section{MATERIAL E MÉTODOS}

Seleção dos acessos. Genótipos selecionados de plantas pertencentes à família Mirtaceae, conhecidas comumente como araçás, nativos e introduzidos de outros países, que compõem o Banco de Germoplasma de Frutíferas Nativas e Exóticas da UNESP/ FCAV, Câmpus de Jaboticabal, e prospectados em 
mata nativa de Uberaba-MG, foram avaliados quanto à reação a $M$. enterolobii e classificados como suscetíveis e resistentes (ALMEIDA et al., 2009). A exceção foi araçá-vermelho ( $P$. cattleyanum) que não foi testado, porém há referências na literatura de que foi resistente ao nematoide em questão (CARNEIRO et al., 2007). Desses acessos, foram selecionados os genótipos descritos na Tabela 1.

Extração de DNA. As folhas jovens coletadas dos acessos foram lavadas, secas com papel toalha e maceradas com $\mathrm{N}$ líquido até a obtenção de pó fino, que foi transferido para tubos eppendorf de $2,0 \mathrm{~mL}$. O DNA das amostras foi extraído conforme o protocolo de Shillito e Saul (1988). A quantificação do DNA e sua qualidade foram realizadas com o auxílio de um espectrofotômetro, medindo-se a absorbância de cada amostra em contraste com uma amostra de $\mathrm{H}_{2} \mathrm{O}$ destilada livre de DNA, nos comprimentos de onda de 260 e $280 \mathrm{~nm}$ (SAMBROOK et al., 1989). A qualidade do DNA foi verificada durante sua quantificação, observando-se a relação encontrada entre as leituras nos comprimentos de onda de 260 e 280 $\mathrm{nm}$, que deve ser entre 1,8 e 2,0, o que caracteriza um DNA de bom peso molecular. Para a certificação da qualidade, amostras do DNA extraído foram aplicadas em gel de agarose a $0,8 \%$ e submetidas à eletroforese para a observação da formação de banda sem arraste.

Obtenção dos marcadores fAFLP. Os marcadores fAFLP foram obtidos utilizando-se do 'fAFLP Regular Plant Genomes Fingerprinting Kit' (Applied Biosystems do Brasil Ltda.), de acordo com instruções do fabricante. O DNA dos isolados foi restrito com as enzimas EcoRI e MseI, ligado aos adaptadores e pré-amplificado. A amplificação seletiva foi realizada com os pares de primers de fluorescência, fluorescência Joe EcoRI-MseI (AGG/ CAC, AAG/CAC, ACG/CTG, ACG/CAC, AGG/ CTT, AAG/CTA, AAG/CAA, ACG/CTC), Ned EcoRI-MseI (AAC/CAT, ACC/CTT, ACC/CAC, $\mathrm{AAC} / \mathrm{CAC}, \mathrm{AGC} / \mathrm{CAA}, \mathrm{AGC} / \mathrm{CTC}, \mathrm{ACC} / \mathrm{CTG}$, AAC/CAG) e fluorescência Fam EcoRI-MseI (ACT/ CAC, ACA/CAC, ACT/CAA, ACA/CTC, ACA/ CTA, ACA/CAG, ACT/CAT, ACT/CTG), totalizando 24 primers. As amostras foram aplicadas em um gel a $5 \%$ desnaturante Long Ranger, usando TEB $1 \mathrm{X}$ como tampão de corrida. Foi utilizada uma placa de sequenciamento de $36 \mathrm{~cm}$ e $2 \mathrm{~h} 30$ de tempo de corrida, a $2.500 \mathrm{~V}$ em um sequenciador automático de DNA (ABI Prism 377), utilizando como padrão de tamanho molecular o GeneScan-500 (ROX).

Análise dos marcadores fAFLP. Foram selecionados fragmentos com tamanho entre 50 e 500 pares de bases. Para a análise dos marcadores, foram utilizados os softwares GeneScan (ABI Prism versão 1.0) e Genotyper (ABI Prism versão 1.03), para a coleta dos dados e transformação dos mesmos em matriz binária. A matriz binária gerada foi analisada no software PAUP (Phylogenetic Analysis Using Parcimony - versão 3.01) (FELSENSTEIN, 1985) para a geração de matriz de distância. A matriz de distância obtida foi analisada pelo software MEGA (versão 2.1). Foram também calculados índices de distância genética intra e interespecífica entre os materiais. Esta é uma medida da diversidade genética existente entre os indivíduos de um grupo (intraespecífica) e em relação a outros grupos ou indivíduos (interespecífica). A mesma matriz de distância obtida foi analisada pelo software MEGA (versão 2.1) (KUMAR et al., 2004), utilizando-se do Método de Distância com algoritmo de agrupamento de Neighbour Joining (SAITOU; NEI, 1987) para a construção do cladograma das relações de similaridade evidenciadas pelos materiais.

\section{RESULTADOS E DISCUSSÃO}

Todos os acessos de araçá utilizados no presente trabalho e submetidos à análise de fAFLP apresentaram amplificação para 18 das 24 combinações seletivas testadas, conforme exemplificado nas Figuras 1 e 2 . Foram obtidos 272 marcadores polimórficos para os 13 acessos deste estudo. As combinações envolvendo fluorescência Joe apresentaram maior eficiência de detecção de variabilidade, medida em função do número de bandas polimórficas, seguidas por Fam e Ned. Observou-se que os acessos 1; 2; 3; 4 e 5 apresentaram grande semelhança no perfil eletroforético. $\mathrm{O}$ mesmo aconteceu em relação aos acessos 6 e 7, que mostraram perfil semelhante entre si e diferente em relação aos demais. $\mathrm{O}$ mesmo se deu para os acessos $8 ; 9$ e 10 . O perfil eletroforético do acesso 11 apresenta alguma similaridade com os acessos 1; 2; 3; 4 e 5 . Os acessos 11 e 12 também demonstraram perfil diferenciado dos demais. $\mathrm{O}$ acesso 13 (goiabeira 'Paluma') mostrou um perfil diferente de todos os acessos de araçazeiro, e por ser de outra espécie foi tratada como padrão de comparação para os demais acessos de araçazeiros do estudo.

Os materiais deste estudo demonstraram distâncias genéticas variando de 0.01103 (menor distância, correspondendo a 3 marcadores) a 0.67279 (maior distância, correspondendo a 183 marcadores) (Tabela 2). A maior distância foi encontrada para os acessos 6 e 7 (P. acutangulum) em relação ao acesso 2 ( $P$. cattleyanum), evidenciando maior diversidade genética, e a menor para os acessos $1 \mathrm{e}$ 3 (P.cattleyanum) e 9 e 10 (P. cattleyanum), com a 
menor variabilidade genética. Os demais materiais apresentaram distâncias intermediárias e, portanto, índices de diversidade genética intermediários.

A análise de agrupamento por similaridade mostrou que os acessos deste estudo apresentaram a formação de 3 grupos distintos, com o acesso 11 apresentando uma posição distinta em relação aos demais, possivelmente em função de sua maior distância média em relação aos demais acessos (Figura 3).

O primeiro grupo foi formado pelos acessos 6 e 7 (araçazeiro 'Pera' 1 e 2, respectivamente) e pelos acessos 12 e 13 (goiaba da Costa Rica e goiabeira 'Paluma', respectivamente). Embora tenham sido identificados pelo mesmo nome, os dois acessos de araçazeiro 'Pera' apresentaram uma pequena distância genética, o que indica que ambos possuem genótipos diferentes, provavelmente em função de sua propagação seminífera e consequente segregação genética. Apesar de classificados em diferentes espécies e apresentarem grande distância genética entre si, os acessos 12 e 13 foram agrupados em um mesmo ramo, embora o comprimento de ramo evidencie um grande número de marcas polimórficas entre ambos.

Os acessos 8; 9 e 10 (Araçazeiro-Vermelho 1; 2 e 3, respectivamente) formaram o segundo grupo do dendrograma, mostrando grande similaridade genética, sendo que os acessos 9 e 10 mostraram similaridade maior entre si do que em relação ao acesso 8. Desta forma, evidencia-se que estes acessos possuem genótipos diferenciados e podem apresentar respostas também diferenciadas em relação à resistência ao nematoide. Segundo Lorenzi et al. (2006), o Araçazeiro-Vermelho ( $P$. cattleyanum Sabine) é a forma típica dessa espécie que apresenta ainda duas outras formas conhecidas como araçazeiro-amarelo por não apresentarem a coloração vermelha da casca dos frutos e do tronco da planta.

Fontes de resistência a $M$. enterolobii foram encontradas entre os genótipos de araçazeiro identificado como $P$. cattleyanum, em três acessos provenientes de Pelotas - RS (CARNEIRO et al., 2007). Os mesmos autores mencionam ainda que eram materiais compatíveis para enxertia com ' $\mathrm{Pa}$ luma', consistindo numa possibilidade de utilizá-los como porta-enxertos para manejo de $M$. enterolobii.

Os acessos de araçá-amarelo ( $P$. cattleyanum) $1 ; 2 ; 3 ; 4$ e 5 agruparam-se formando o terceiro grupo, embora estejam dispostos em dois subgrupos. Um dos subgrupos foi formado pelos acessos 1; 3 e 5, enquanto o outro foi formado pelos acessos 2 e 4. Desta forma, evidencia-se que estes materiais, apesar da formação de subgrupos, apresentam uma distância genética menor, embora apresentem genótipos distintos. Salienta-se que essas plantas são provenientes de propagação seminífera, o que representa segregação genética.

Fontes de resistência a $M$. enterolobii foram encontradas entre os acessos pertencentes à Coleção de Fruteiras Nativas e Exóticas da UNESP/FCAV, sendo que os acessos 1; 2 e 5 de araçazeiro-amarelo mostraram alto grau de resistência genética quando inoculados com o nematoide (ALMEIDA et al., 2009). Os mesmos autores também verificaram que os acessos 3 e 4 foram suscetíveis a M. enterolobii. Já o acesso 12, da espécie $P$. friedrichsthalianium, apresentou comportamento diferenciado, sendo relatado como resistente a $M$. incognita e $M$. javanica (MARANHÃO et al., 2001) e também como suscetível a M. enterolobii (ALMEIDA et al., 2009).

Os marcadores fAFLP foram eficientes em agrupar os acessos deste estudo de acordo com sua similaridade genética e também aproximaram materiais com características de resistência ao nematoide, como no caso dos isolados $P$. cattleyanum vermelho e $P$. cattleyanum amarelo, embora os acessos 3 e 4 não tenham apresentado esta característica.

Apesar da característica de resistência apresentada, nenhum acesso pertencente ao araçazeiro-amarelo (P. cattleyanum) apresentou compatibilidade para enxertia com goiabeira 'Paluma' (ALMEIDA, 2008), o que inviabiliza a utilização destes materiais como porta-enxerto. Entretanto, o conhecimento de fontes de resistência pode ser futuramente explorado através do isolamento destes genes e sua posterior transferência através de técnicas biotecnológicas para a goiabeira. 
TABELA 1- Acessos de Psidium utilizados no estudo, com os respectivos nomes científicos e origem geográfica.

\begin{tabular}{cccc}
\hline $\begin{array}{c}\text { Número do } \\
\text { Acesso }\end{array}$ & Nome & Nome científico & Origem \\
\hline 1 & Araçazeiro acesso 1.1 & Psidium cattleyanum & FCAV/UNESP \\
2 & Araçazeiro acesso 1.2 & Psidium cattleyanum & FCAV/UNESP \\
3 & Araçazeiro acesso 1.3 & Psidium cattleyanum & FCAV/UNESP \\
4 & Araçazeiro acesso 1.4 & Psidium cattleyanum & Taquaritinga-SP \\
5 & Araçazeiro acesso 6.1 & Psidium cattleyanum & Uberaba-MG \\
6 & Araçazeiro-Pera 1 & Psidium acutangulum & FCAV/UNESP \\
7 & Araçazeiro-Pera 2 & Psidium acutangulum & FCAV/UNESP \\
8 & Araçazeiro-Vermelho 1 & Psidium cattleyanum & FCAV/UNESP \\
9 & Araçazeiro-Vermelho 2 & Psidium cattleyanum & FCAV/UNESP \\
10 & Araçazeiro-Vermelho 3 & Psidium cattleyanum & FCAV/UNESP \\
11 & Araçazeiro-Uberaba & Psidium sp. & Uberaba -MG \\
12 & Goiabeira da Costa Rica & Psidium friedrichsthalianium & FCAV/UNESP \\
13 & Goiabeira Paluma & Psidium guajava & FCAV/UNESP \\
\hline
\end{tabular}

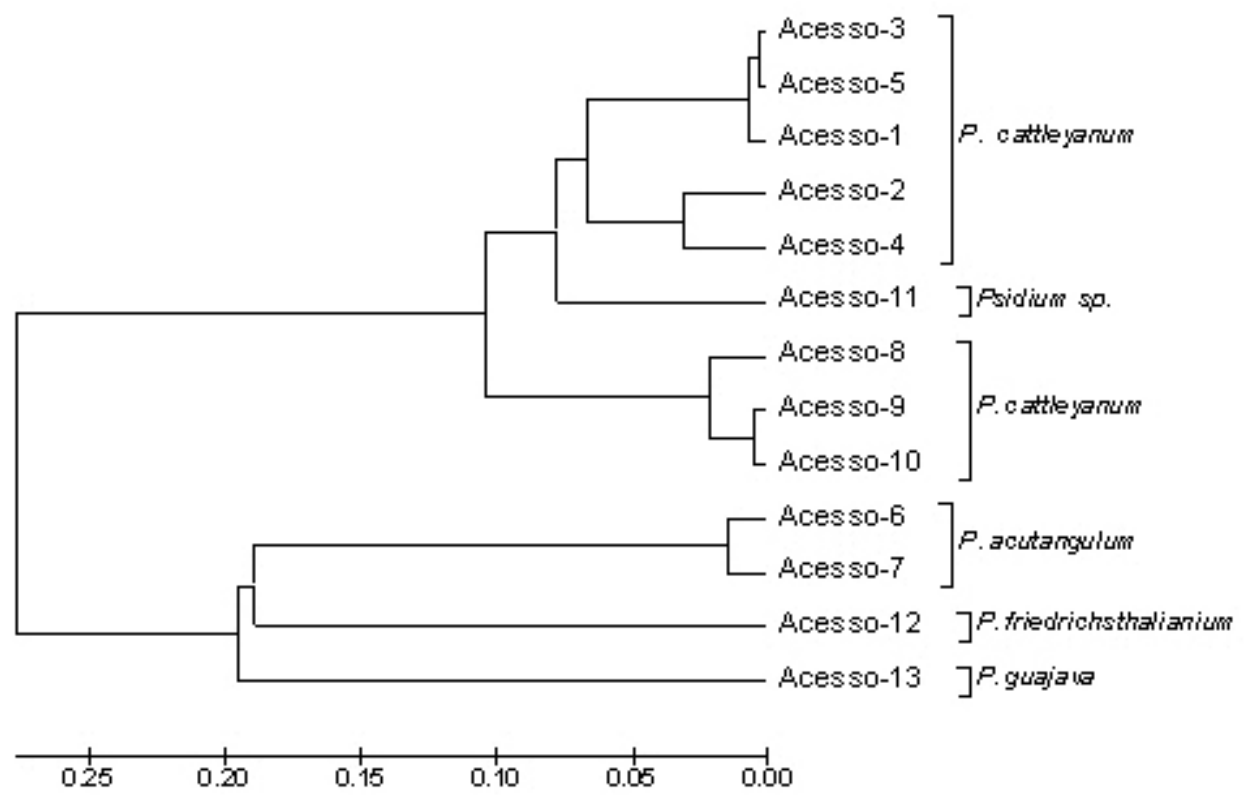

FIGURA 1 - Dendograma das relações filogenéticas encontradas para os acessos de Psidium deste estudo. 
TABELA 2- Número médio das diferenças obtidas entre os acessos (parte superior) e número total de marcadores polimórficos observados entre os acessos de Psidium spp. (Mirtáceas) (parte inferior).

Acesso Acesso Acesso Acesso Acesso Acesso Acesso Acesso Acesso Acesso Acesso Acesso Acesso

\begin{tabular}{lllllllllllll}
1 & 2 & 3 & 4 & 5 & 6 & 7 & 8 & 9 & 10 & 11 & 12 & 13 \\
\hline
\end{tabular}

\begin{tabular}{|c|c|c|c|c|c|c|c|c|c|c|c|c|c|}
\hline $\begin{array}{c}\text { Acesso } \\
1\end{array}$ & - & 0.1617 & 0.01103 & 30.10662 & 20.01838 & 80.60662 & 0.60662 & 20.20221 & 10.20588 & 0.20956 & 0.12868 & 0.49265 & 50.51103 \\
\hline $\begin{array}{c}\text { Acesso } \\
2\end{array}$ & 44 & - & 0.16544 & 40.06250 & 0.1654 & 40.67279 & 0.67279 & 90.26103 & 30.27206 & 0.26103 & 0.23162 & 0.56618 & 80.59926 \\
\hline $\begin{array}{c}\text { Acesso } \\
3\end{array}$ & 3 & 45 & - & 0.1029 & 40.0073 & 50.60294 & 40.60294 & 40.19118 & 80.19485 & 0.19853 & 0.11765 & 0.48897 & 70.52206 \\
\hline $\begin{array}{c}\text { Acesso } \\
4\end{array}$ & 29 & 17 & 28 & - & 0.1029 & 40.66176 & 0.66176 & 60.22059 & 90.23162 & 0.22059 & 0.18382 & 0.54044 & 40.58088 \\
\hline $\begin{array}{c}\text { Acesso } \\
5\end{array}$ & 5 & 45 & 2 & 28 & - & 0.59559 & 0.60294 & 40.19118 & 80.19485 & 0.19853 & 0.11765 & 0.49632 & 20.52206 \\
\hline $\begin{array}{c}\text { Acesso } \\
6\end{array}$ & 165 & 183 & 164 & 180 & 162 & - & 0.02941 & 10.58824 & 40.56250 & 0.56618 & 0.56618 & 0.37868 & 80.42647 \\
\hline $\begin{array}{c}\text { Acesso } \\
7\end{array}$ & 165 & 183 & 164 & 180 & 164 & 8 & - & 0.58824 & 40.56250 & 0.56618 & 0.56618 & 0.37868 & 80.42647 \\
\hline $\begin{array}{c}\text { Acesso } \\
8\end{array}$ & 55 & 71 & 52 & 60 & 52 & 160 & 160 & - & 0.04044 & 0.04412 & 0.18382 & 0.45956 & 60.52206 \\
\hline $\begin{array}{c}\text { Acesso } \\
9\end{array}$ & 56 & 74 & 53 & 63 & 53 & 153 & 153 & 11 & - & 0.01103 & 0.15809 & 0.42647 & 70.48897 \\
\hline $\begin{array}{c}\text { Acesso } \\
10\end{array}$ & 57 & 71 & 54 & 60 & 54 & 154 & 154 & 12 & 3 & - & 0.15441 & 0.43015 & 50.49265 \\
\hline $\begin{array}{c}\text { Acesso } \\
11\end{array}$ & 35 & 63 & 32 & 50 & 32 & 154 & 154 & 50 & 43 & 42 & - & 0.43015 & 50.49265 \\
\hline $\begin{array}{c}\text { Acesso } \\
12\end{array}$ & 134 & 154 & 133 & 147 & 135 & 103 & 103 & 125 & 116 & 117 & 117 & - & 0.31985 \\
\hline $\begin{array}{c}\text { Acesso } \\
13\end{array}$ & 149 & 163 & 142 & 158 & 142 & 116 & 116 & 142 & 133 & 134 & 134 & 87 & - \\
\hline
\end{tabular}



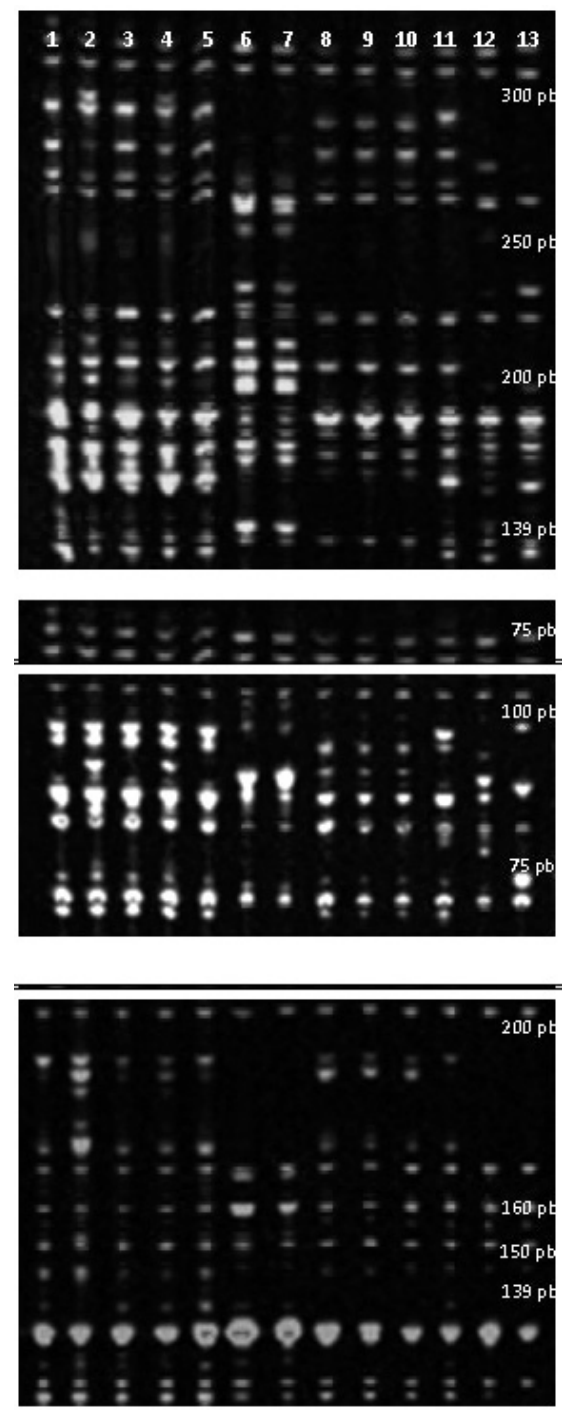

FIGURA 2 - Perfil eletroforético dos 13 acessos de Psidium analisados com as combinações EcoRI-MseI Joe - AGG/CAG (verde), Ned - ACC/CAC (amarelo) e Fam - ACT/CAC Azul). Em vermelho, o marcador de tamanho molecular ROX-500.

\section{CONCLUSÃO}

Os marcadores fAFLP são eficientes em agrupar os acessos de araçazeiro de acordo com a espécie e aproximam os acessos considerados resistentes ao nematoide M. enterolobii.

\section{AGRADECIMENTOS}

À Fundação de Amparo à Pesquisa do Estado de São Paulo (FAPESP), pelo Auxílio à Pesquisa concedido a este trabalho.

\section{REFERÊNCIAS}

ALMEIDA, E.J. O nematoide de galha da goiabeira (Meloidogyne mayaguensis Rammah \& Hirschmann, 1988): identificação, hospedeiros e ação patogênica sobre goiabeiras. 2008. 98f. Tese (Doutorado em Agronomia) - Faculdade de Ciências Agrárias e Veterinárias, Universidade Estadual Paulista, Jaboticabal, 2008.

ALMEIDA, E.J.; MARTINS, A.B.G.; SANTOS, J.M. Resistência de goiabeiras e araçazeiros a $\mathrm{Me}$ loidogyne mayaguensis e estudo da compatibilidade na enxertia. Pesquisa Agropecuária Brasileira, Brasília, v.44, n.4, p.421-423, 2009. 
AUKAR, A.P.A. Identificação de marcadores cDNA e fAFLP em genótipos de Coffea spp. resistentes a Meloidogyne incognita (Nemata: Heteroderidae). 2003, 75f. Tese (Doutorado em Agronomia) - Faculdade de Ciências Agrárias e Veterinárias, Universidade Estadual Paulista, Jaboticabal, 2003.

CARNEIRO, R.M.D.G.; CIROTTO, P.A.; QUINTANILHA, A.P.; SILVA, D.B.; CARNEIRO, R.G. Resistance to Meloidogyne mayaguensis in Psidium spp. accessions and their grafting compatibility with P. guajava cv. Paluma. Fitopatologia Brasileira, Brasília, v.32, n.4, p.281-284, 2007.

FELSENSTEIN, J. Confidence limits on phylogenies: An Approacch using the bootstrap. Evolution, Lawrence, v.39, p.783-790, 1985.

FERREIRA, M.; GRATTAPAGLIA, D.E. Introdução ao uso de marcadores moleculares em análise genética. Brasília: EMBRAPA-CENARGEN, 1998.

HARTMAN, H.T.; KESTER, D.E.; DAVIES JR., F.T.; GENEVE, R.L. Plant propagation: principles and practices. $6^{\text {th }}$ ed. New Jersey: Prentice Hall, 1997. $770 \mathrm{p}$.

KUMAR, S.; TAMURA, K.; NEI, M. MEGA: Integrated software for Molecular Evolutionary Genetics Analysis and sequence alignment. Briefings in Bioinformatics, London, n.5, p.150-163, 2004.

LORENZI, H.; BARCHER, L.; LACERDA, M.; SARTORI, S. Frutas brasileiras e exóticas cultivadas. São Paulo: Instituto Plantarum de Estudos da Flora, 2006. 640p.

MARANHÃO, S.R.V.L.; MOURA, R.M.; PEDROZA, E.M.R. Reação de indivíduos segregantes de araçazeiro a Meloidogyne incognita, M. javanica e M. mayaguensis. Fitopatologia Brasileira, Brasília, v.27, p.191, 2001. Suplemento.

PEREIRA, F.M.; NACHTIGAL, J.C. Melhoramento da goiabeira. In: ROZANE, D.E.; COUTO, F.A.d'A. Cultura da goiabeira: tecnologia e mercado. Viçosa: UFV, 2003. p.53-78.
PEREIRA, F.O.M.; SOUZA, R.M.; SOUZA, P.M.; DOLINSKI, C.; SANTOS, G.K. Estimativa do Impacto Econômico e Social Direto de Meloidogyne mayaguensis na Cultura da Goiaba no Brasil. Nematologia Brasileira, Piracicaba, v. 33, n 2, p. 176-181, 2009.

RAMMAH, A.; HIRSCHMANN, H. Meloidogyne mayaguensis $\mathrm{n}$. $\mathrm{sp}$. (Meloidogynidae), a Root-knot Nematode from Puerto Rico. Journal of Nematology, College Park, v.20, n.1, p.58-69, 1988.

ROBERTS, P. A.; MATTHEWS, W. C.; VEREMS, J. C. Genetic mechanisms of host-plant resistance to nematodes. In: BARKER, K. R.; PEDERSON, G. A.; WINDHAM, G.L. (Ed.). Plant nematode interactions. Madison: American Society of Agronomy, 1998. p. 209-238.

ROZANE, D.E.; COUTO, F.A.d'A. (Ed.). Cultura da goiabeira: tecnologia e mercado. Viçosa: UFV, 2003. $402 \mathrm{p}$.

SAITOU, N.; NEI, M. The neighbor-joining method: A new method for reconstructing phylogenetic trees. Molecular Biology and Evolution, Chicago, v.4, p.406-425, 1987.

SAMBROOK, J.; MANIATIS, T.; FRITSH, E.F. Molecular cloning: a laboratory manual. $2^{\text {nd }}$ ed. New York: Cold Sprig Harbor Laboratory, 1989.

SHILLITO, R.D.; SAUL, M.W. Protoplast isolation and transformation. In: SCHAN, C.H. (Ed.) Plant molecular biology: a practical approach. Oxford: IRL Press, 1988. p.161-186.

SOUZA, R.M.; NOGUEIRA, M.S.; LIMA, I.M.; MELARATO, M.; DOLINSKI, C.M. Manejo do nematoide das galhas da goiabeira em São João da Barra (RJ) e relato de novos hospedeiros. Nematologia Brasileira, Brasília, v.30, n.1, p.165-169, 2006.

WEISING, K.; NYBOM, H.; WOLFF, K.; MEYER, W. DNA fingerprinting in plants and fungi. New York: CRC Press, 1995. 322p. 